\title{
CAESAREAN SECTION -WHY IS IT PERFORMED SO OFTEN?
}

\author{
Bangal Vidyadhar $\mathrm{B}^{1} *$, Giri Purushottam $\mathrm{A}^{2}$, Chandaliya Rajiv $\mathrm{M}^{3}$ \\ *Prof.Obst Gyn ${ }^{1}$, Associate Prof PSM ${ }^{2}$,Postgraduate student Obst Gyn ${ }^{3}$ \\ Rural Medical College, Loni, Ahmednagar, Maharashtra
}

\begin{abstract}
Caesarean section is the most frequently performed major surgery in modern Obstetrics. The rate of caesarean section have shown significant rise in last three decades. This trend is seen all over the world .This has some serious implications on the risk of scar rupture and resultant rise in maternal and perinatal morbidity and mortality .This paper summarizes the changing trends and the reasons behind it. Obstetrician must keep in mind the possible threats of rise in caesarean section rates and must perform this procedure judiciously.
\end{abstract}

Keywords: Caesarean section, Scar rupture, Rupture uterus, maternal mortality,

\section{INTRODUCTION}

Caesarean Section (CS) is an operation, mainly evolved to save a maternal life during difficult child birth. It has now become increasingly the procedure of choice in high risk pregnancies, to prevent perinatal morbidity and mortality. This has become possible due to improved patient care, availability of effective antibiotics, blood transfusion services, safer anesthesia, improved surgical technique and sophisticated neonatal care services.National discharge survey in USA showed that the incidence of caesarean section in USA in 1970 was 5.5\%, which then increased to $40 \%$ in 2000 AD[1]. The common indications reported were elderly primi and repeat caesarean section. Broad survey by National center for health statistics reported, highest incidence of caesarean section (20\%) in USA \& lowest (6\%) in Czechoslovakia[2]. There have also been reports of rising trends of Caesarean section from Indian literature (Table 1)[3,4,5,6,].There is no evidence to support any specific target rate. However, recent drive in America to reduce caesarean section rate to $15 \%$ has been criticized for causing increased maternal and fetal damage. At the same time, the alarming rise in the rate of caesarean has been a matter of concern to the profession and the public. Health professionals and the health providers have now started questioning, whether such an increase in the rate of caesarean section is truly justified? World health organization (WHO) set the limit of $10 \%$ caesarean section rate, rather than $15 \%$. According to $\mathrm{WHO}$, there is no justification for any reason to have caesarean rate higher than $10-15 \%$. The incidence of caesarean in India varies widely with recent marked upward swing with increased safety of caesarean, the quality of results in terms of maternal and fetal trauma is being increasingly appreciated so that heroic measures to deliver a live child per via naturalis has been given up (Table 2 ). Greatest emphasis attached to fetal welfare in today's small family era has changed the delivery practices in favor of caesarean section. This revised attitude has lead to the emergence of a new set of indications for adopting caesarean section as a preferred mode of delivery (Table 3).

Table 1: Rising Rates of Caesarean Section from Indian Literature

\begin{tabular}{|c|c|c|}
\hline Author / Place & $\begin{array}{l}\text { Studies before } \\
1980\end{array}$ & $\begin{array}{l}\text { Studies } \\
1980\end{array}$ \\
\hline $\begin{array}{l}\text { Rao K Bhaskar [3] } \\
\text { Madras Medical college }\end{array}$ & $\begin{array}{l}3-6 \% \\
(1970)\end{array}$ & $\begin{array}{l}16.2 \% \\
(1983)\end{array}$ \\
\hline $\begin{array}{l}\text { Deshmukh M.A.[4] } \\
\text { KEM Hospital Bombay }\end{array}$ & $\begin{array}{l}1.95 \% \\
(1971)\end{array}$ & $\begin{array}{ll}5.5 \%, & 14.9 \% \\
(1981) & (1999)\end{array}$ \\
\hline $\begin{array}{l}\text { Daftary S.[5] } \\
\text { Wadia Hospital Bombay }\end{array}$ & $\begin{array}{l}3.6 \% \\
(1970)\end{array}$ & $\begin{array}{l}16.05 \\
(1998)\end{array}$ \\
\hline $\begin{array}{l}\text { Arora R.[6] } \\
\text { JIPMER Pondicherry }\end{array}$ & $\begin{array}{l}12.33 \% \\
(1978)\end{array}$ & $\begin{array}{l}27.6 \% \\
(2000)\end{array}$ \\
\hline
\end{tabular}


IOSR Journal of Pharmacy

Vol. 2, Issue 3, May-June, 2012, PP.534-536

Table 2: Reasons for Rising Rates of Caesarean Section

$>$-Increasingly frequent diagnosis of fetal distress on electronic fetal heart rate monitoring.

$>$-Increased use of Caesarean section in Breech presentation

$>$-Frequent resort to elective section in high risk situation.

$>$-To avoid difficult manipulative or instrumental vaginal deliveries.

$>$-Precious pregnancy

$>$-Identification of high risk mothers

$>$-Patient / doctor convenience

$>$-Fear of Litigation

$>$-Desire for concomitant tubectomy.

$>$-Adaptation of small family norm -neither obstetrician nor the patients desire to take even

$>$ slightest extra risk of abnormal labour and adverse outcome.

Table .3 Newer indications of caesarean section

$>$ An increasing number of repeat Caesarean sections.

$>$ Increasingly frequent diagnosis of fetal distress on electronic fetal heart rate monitoring.

$>$ Increased use of Caesarean section in Breech presentation

$>$ Frequent resort to elective section in high risk situation.

$>$ To avoid difficult manipulative or instrumental vaginal deliveries.

$>$ Precious pregnancy

$>$ Identification of high risk mothers

$>$ Patient / doctor convenience

$>$ Fear of Litigation

$>$ Desire for concomitant tubectomy.

$>$ Adaptation of small family norm -neither obstetrician nor the patients desire to take

$>$ even slightest extra risk of abnormal labour and adverse outcome.

$>$ Increasing survival rates of very small infants following Caesarean section.

1.1. Some of the common indications of caesarean section are as follows:

a. Previous caesarean section - accounts for 8-40\% of repeat caesarean section. Craigins (1916) dictum of "once a Caesarean section always a Caesarean section" was misquoted and misapplied. In those days, classical caesarean section was popular and blood transfusion facilities were not available. Today, the dictum has changed to 'Previous caesarean section, always an institutional delivery'.[7] Many cases (33-75\%) of previous caesarean section, can be delivered vaginally (Vaginal birth after caesarean section -VBAC), when the indication of previous caesarean section was non recurrent.[8] The old notion that Caesarean section converts the mother into an obstetric cripple is now obsolete.

b. Fetal distress - accounts for 5-6\% of caesarean section. Incidence is increased after electronic fetal monitoring and fetal scalp blood sampling.[9]

c. Breech presentation - has got inherent risk of vaginal delivery. The risk is uncertain or unpredictable. Soni (1931) suggested that caesarean section would reduce the perinatal mortality in breech.

d. Ante partum haemorrhage - Caesarean section for both placenta praevia and abruption, when baby is mature and alive, resulted in reduction in maternal morbidity and improved fetal salvage rates.

e. Twins - Cesarean section, where first baby's presentation is other than vertex, conception following assisted reproductive techniques and for second of the twins.

f. Very low birth weight babies - There is reduction in incidence of intra-ventricular hemorrhage in very low birth weight babies delivered by Caesarean section, than delivered by vaginal route. Increasing survival rates of very small infants further resulted in increasing Caesarean section rates.

g. Elective caesarean section -Women's right to choose?

When choice /preference /opinion of women is respected in other areas like infertility treatment, fertility control etc, then how can we discredit 'positive right' in the context of patients choice of caesarean section?

Our lives are more safe and controlled now than ever before. It is therefore understandable that some people will request a controlled and safe method of delivery of their baby. Evidence regarding safety of elective Caesarean section verses vaginal delivery remains grossly incomplete. Risk of maternal death directly attributable to caesarean section and vaginal delivery is 5.8/100,000 Caesarean section and 10.8/100,000 vaginal deliveries respectively.[10]The rise in the rates of caesarean section witnessed over the last 3 decades was essentially aimed at bringing down perinatal mortality rates, particularly in cases of fetal distress, intrauterine growth restriction, breech presentations and for very low birth weight babies. 


\section{CONCLUSION}

Traditionally, Caesarean sections have been reserved for those situations, where labor or vaginal deliveries have been considered dangerous to either mother or baby. Today in modern obstetrics, with increase in primary caesarean sections and adoption of small family norms, improved fetal outcome in cases of very low birth babies, breeches and in intrauterine growth restricted babies following Caesarean section, the incidence of Caesarean section is rising. There is no evidence to support any specific rate of cesarean section. Ultimately, what matters most is that, those women and babies who need Caesarean section, get it; while those who do not need, are saved from unnecessary surgery.

\section{REFERENCES}

[1]. Myers SA, Gleicher N: High caesarean section rates among women over $30 \mathrm{yrs}$. N. England J. Med 1988;319:1511

[2]. Notzen FC, Plack PJ, Taffel SM; Controlling the rise in caesarean section rates. N. England J. Med. $1987 ; 316: 386$

[3]. Rao K Bhaskar et al; Caesarean section: recent trends. Obst and Gyn for postgraduates 1;1992

[4]. Deshmukh M A ; High caesarean section rate. A new perspective. J. Obstet Gynaecol 1985;35:451

[5]. Daftary Shirish, Patki Amit; Pregnancy at Risk: Caesarean section in present day practice. $4^{\text {th }}$ edn2001;page 446

[6]. Arora R, Oomaguichi A; why are caesarean section rates increasing so rapidly? J. Obstet Gynaecol 1991;141:192

[7]. Phelan J, Clark SL, Diaz F et al: Recent trends in caesarean section rates in Ontario. Am J Obstet Gynaecol 1987; 157:1510

[8]. Martin JN Jr, Perry KG jr, Roberts WE et al: Caesarean section rate climbs in US despite governments efforts in reduction. Am J Obstet Gynaecol 1997;177:144

[9]. Dhake A, Lohana A, Purandare CN et al; Factors related to high caesarean section rate. J Obstet Gynaecol India 1995;45:218

[10]. Singh J, Lakshmi devi Y ; Relentless rise in caesarea section rate. J Obstet Gynaecol 1984;34:849. 